\title{
Trips Agreement Dan Standarisasi Hukum Perlindungan Hak Kekayaan Industri Di Indonesia
}

\author{
Rani Fadhila Syafrinaldi ${ }^{1,}$ David Hardiago ${ }^{2}$ \\ 1. Faculty of Law, Universitas Gajah Mada. E-mail: ranisyafrinaldi@mail.ugm.ac.id \\ 2. Faculty of Law, Universitas Gajah Mada. E-mail: davidhardiago@mail.ugm.ac.id
}

\begin{abstract}
Trade Related Aspects of Intellectual Property Right Agreement 1995 (TRPS Agreement) is an international provision in the field of intellectual property rights protection that applies universally. Indonesia as a country of law, has all laws relating to the protection of intellectual property rights with reference to the TRIPS Agreement. The TRIPS Agreemnt formulation must also refer to the Paris Convention For the Protection of Industrial Property, 1883 which has been recognized as the legal basis for the protection of intellectual property rights globally. Protection of industrial assets consisting of Patents, Trademarks, Trade Secrets, Industrial designs, Protection of Plant Varieties and Layout Designs of Integrated Circuits must be carried out by the state towards the holders of the said industrial property rights.
\end{abstract}

Keywords: Earth, Water, Natural wealth, Right to rule, State

\section{Pendahuluan}

Perlindungan hukum terhadap hak kekayaan seseorang yang diberikan oleh negara sangat penting sekali dalam konteks negara hukum. Perlindungan hukum serupa juga harus diberikan terhadap hak kekayaan intelektual ${ }^{1}$. Sebab kedua bentuk hak kekayaan tersebut pada hakekatnya adalah sama, karena sama-sama menjadi obyek hukum atau sesuatu yang dapat dimiliki dan dikuasai oleh subyek hukum, baik secara sendiri-sendiri maupun secara bersama-sama.

Jauh sebelum adanya Trade Related Aspects of Intellectual Property Right Agreement 1995 (TRPS Agreement), sudah banyak negara-negara yang pada awal abad ke 19 memiliki legislasi nasional dalam memberikan perlindungan terhadap paten, misanya negara Perancis, Swis, Jerman dan lainnya. Masing-masing legislasi nasional negaranegara tersebut memiliki ketentuan yang berbeda-beda satu sama lainnya tentang perlindungan hukum paten tersebut seperti jangka waktu perlindungan paten. Faktor inilah yang menjadi penguat untuk munculnya semngat kebersamaan negara-negara di Eropah untuk mengakhiri perbedaan tersebut dengan menggelar Paris Conference yang pada akhirnya menghasilkan Paris Convention For The Protection of Industrial Property, 1883 (Paris Convention). Dengan demikian dapat dikatakan bahwa Paris Convention 1883 sudah meletakkan dasar-dasar persamaan mengenai hukum perlindungan kekayaan

1 Lebih jauh lihat Syafrinaldi, Hukum Tentang Perlindungan Hak Kekayaan Intelektual Dalam Menghadapi Era Globalisasi, UIR Press, 2010, hlm. 1 dstnya. 
intelektual, khususnya kekayaan industri sehingga tepat untuk dikatakan dengan konsep awal lahirnya globalisasi hukum².

Di era globalisa dan teknologi informasi, arus keluar masuk barang dan jasa dari satu tempat ke tempat lain dalam satu negara atau dari satu negara ke negara lainnya merupakan fenomena yang sudah biasa dan bahkan kegiatan-kegiatan transaksi antar negara sudah memasuki era baru yang disebut dengan Electronic Commerce (ECommerce). Konsumen sudah banyak meninggalkan cara-cara yang konvensional dalam memenuhi kebutuhan hidupnya dengan beralih ke cara-cara modern yang disebut dengan online shopping.

Globalisasi pada hakekatnya merupakan ciri dari masyarakat modern dengan didukung oleh maju pesatnya perkembangan dan kemajuan ilmu pengetahuan dan teknologi (informasi) ${ }^{3}$. Globalisasi juga telah melenyapkan batas-batas negara dan akhirnya menimbulkan kesamaan keadaan di setiap negara di muka bumi ini.

Dalam bidang hak kekayaan intelektual kesamaan barang dan jasa yang diperdagangkan lintas negara memerlukan konsep dan standar hukum perlindungan yang sama pula. Dalam rangka itu sejak tahun 1883 telah diciptakan dan dirumuskan standarisasi hukum perlindungan hak kekayaan intelektual secara global dengan disetujuinya Paris Convention for the Protection of Industrial Property 4 .

Globalisasi hukum yang berkaitan dengan perdagangan internasional dan hak kekayaan intelektual semakin gencar dilakukan dengan disetujuinya Agreement Establishing the World Trade Organization (WTO) $)^{5}$ pada tanggal 15 April 1994 beserta dengan lampiran ketentuan hukum internasional penting lainnya seperti Trade Related Aspects of Intellectual Property Rights Agreement (TRIPS). WTO is treated as rules of trade between nations at a global level dan mekekayaani semangat yang tinggi untuk menghapuskan segala praktek bisnis curang (unfair trade).

Baik barang maupun jasa yang merupakan produk intelektual manusia telah memainkan peran yang sangat menentukan dalam perdagangan internasional dewasa ini dan akan terus meningkat pada masa-masa yang akan datang ${ }^{6}$. Seiring dengan itu nilai ekonomi yang terdapat pada karya-karya intelektual manusia itu, khususnya dalam bidang

2 G. Galvez-Behar, The 1883 Paris Convention and the Impossible Unification of Industrial Property in: G. Gooday and S. Wilf (Ed.), Patent Cultures, Cambridge University Press, 2020, hlm. 38 dstnya.

${ }^{3}$ Lihat Syafrinaldi, Menuju Era Hak Kekayaan Intelektual, Makalah disampaikan pada Kuliah Umum Mahasiswa Baru Universitas Islam Riau TA 2000/2001, 28 Agustus 2000.

4 Konvensi Paris 1883 telah beberapa kali dirubah dan hingga kini masih berlaku sebagai standar hukum yang harus dipatuhi oleh negara-negara dalam perumusan legislasi nasionalnya dalam bidang hak kekayaan intelektual.

5 WTO merupakan hasil dari Uruguay Rounds of Negotiation dari lebih seratus negara yang memakan waktu cukup panjang dan melelahkan, yakni dari tahun 1986 sampai tahun 1994. Perjanjian WTO ini mulai diberlakukan pada 1 Januari 1995 dan 148 negara sudah menjadi anggota WTO sampai dengan tanggal 13 Opktober 2004; lihat www.wto.int. Indonesia menjadi anggota WTO sejak 1 januari 1995 setelah Indonesia meratifikasi WTO Agreement dengan UU No. 7 Tahun 1994.

6 European Commission, Strategic Dimensions of Intellectual Property Rights in the Context of S\&T Policy, Belgium, June 1999, 14. Hal ini sejalan dengan perkembangan ilmu pengetahuan dan teknologi di era revolusi industry 4.0 . 
industri ${ }^{7}$ telah menjadi factor penentu dalam pembangunan dan pertumbuhan ekonomi local, nasional dan global. Oleh sebab itu, hal ini telah menimbulkan suatu kebutuhan yang sama pada tataran masyarakat internasional untuk memberikan perlindungan hukum yang sama dan seragam di setiap negara dengan mengacu pada TRIPS Agreement 1995. Dengan demikian dapat dikatakan bahwa dengan adanya standarisasi hukum dalam bidang perlindungan hak kekayaan industri ini telah melahirkan suatu konsep hukum baru yakni globalisasi hukum.

Indonesia sebagai negara baru yang lahir di pertengan abad ke 20 tumbuh menjadi negara besar di kawasan asia Tenggara (ASEAN) setidaknya dilihat dari sisi luas wilayah dan jumlah penduduknya. Di bidang hak kekayaan intelektual, komitmen dapat dilihat dari beberapa pasal dari Undang-Undang Dasar 1945 sebagai hukum dasar tertulis yang mengatur dan mengakui hak kekayaan intelektual sebagai bagian dari hak asasi manusia (human rights). Kemudian pada tahun 1961 merupakan tahun bersejarah bagi Indonesia karena untuk pertama kalinya Indonesia memiliki Undang-Undang yang dibuat oleh parlemen dengan mengesahkan UU No 21 Tahun 1961 Tentang Paten.

Tulisan ini mencoba untuk menganalisis mengenai keterkaitan antara dan Paris Convention 1883 dan TRIPS Agreement 1995 dan standarisasi perlindungan hukum hak ekonomi menurut TRIPS Agreement dan Ketentuan dalam bidang Kekayaan Industri di Indonesia.

7 Hak kekayaan industri ini terdiri dari Paten, Merek, Rahasia Dagang, Desain Industri, Desain tata Letak Sirkuit Terpadu dan Perlindungan Varietas Tanaman. 


\section{Pembahasan}

\section{A. Kaitan Paris Convention 1883 dan TRIPS Agreement 1995}

Hubungan antara Paris Convention $1883^{8}$ dan TRIPS Agreement bagaikan hubungan antara saudara tua dan muda yang saling melengkapi. Sebagai ketentuan hukum internasional multilateral yang tertua Paris Convention telah meletakkan prinsip-prinsip dasar secara yuridis yang telah membuka cakrawala manusia di jagad raya untuk memberikan penghargaan dan perlindungan terhadap karya-karya intelektual manusia. Sedangkan TRIPS Agreement yang dilahirkan pada tanggal 15 April 1994 di Marakesh, Maroko dan diberlakukan sejak 1 Januari 1995 memberikan ketegasan mengenai bidang-bidang dari hak kekayaan intelektual dan prinsip-prinsip hukum yang applicable serta kaitannya dengan perdagangan internasional ${ }^{9}$. Kedua-duanya saling melengkapi dan tidak dapat dipisahkan satu sama lainnya.

Paris Convention sejak disetujui pada tanggal 20 Maret 1883 telah beberapa kali mengalami perubahan seiring dengan kemajuan ilmu pengetahuan dan teknologi serta perkembangan dalam bidang hak kekayaan perindustrian itu sendiri. Perubahan-perubahan itu dapat dilihat sebagai berikut :

a Perubahan pertama pada tanggal 14 Desember 1900 dalam pertemuan di Brussel, Belgia;

b Perubahan kedua pada tanggal 2 Juni 1911 di Washington DC, Amerika Serikat;

c Perubahan ketiga pada tanggal 6 Nopember 1925 di Den Haag, Belanda;

d Perubahan keempat pada tanggal 2 Juni 1934 di London, Inggris;

e Perubahan kelima pada tanggal 31 Oktober 1958 di Lisbon, Portugal;

f Perubahan keenam pada tanggal 14 Juli 1967 di Stockholm, Swedia; dan

g Perubahan ketujuh pada tanggal 2 Oktober 1979 Stockholm.

Mengenai ruang lingkup Paris Convention 1883 dapat dilihat pada Pasal 1 sebagaimana dikutip dibawah ini.

1) The countries to which this Convention applies constitute a Union for the protection of industrial property.

2) The protection of industrial property has its object patents, utility models, industrial designs, trademarks, service marks, trade names, indications of source or appellations of origin, and the repression of unfair competition.

3) Industrial property shall be understood in the broadest sense and shall apply not only to industry and commerce proper, but likewise to agricultural and extractive industries and to all manufactured or natural products, for example, wines, grain, tobacco leaf, fruit, cattle, minerals, mineral waters, beer, flowers, and flour.

8 G. Galvez-Behar, The 1883 Paris Convention and the Impossible Unification of Industrial Property in: G. Gooday and S. Wilf (Ed.), loc cit.

9 N. W. Loon, Law of Intellectual Property of Singapore, Thomson Sweet \& Maxwell Asia, 2008, Hlm. 45. 
4) Patents shall include the various kinds of industrial patents recognized by the laws of the countries of the Union, such as patents of importation, patents of improvement, patents, and certificates of addition, etc.

Hubungan kedua ketentuan hukum internasional itu juga dapat dilihat pada Pasal 1 Ayat (3) TRIPS: "Members shall accord the treatment provided for in this Agreement to the nationals of other Members. In respect of the relevant intellectual property rights, the nationals of other Members shall be understood as those natural or legal persons that would meet the criteria for eligibility for protection provided for in the Paris Convention(1967), ...."Pasal 2 TRIPS lebih lanjut menyebutkan hubungan tersebut sebagai berikut:

1) In respect of Parts II, III, and IV of this Agreement, Members shall comply with Articles $1-12$ and 19 of the Paris Convention (1967).

2) Nothing in Part I to IV of this Agreement shall derogate from existing obligations that Members may have to each other under the Paris Convention, the Berne Convention, the Rome Convention and the Treaty on Intellectual Property in respect of Integrated Circuits.

Dengan demikian hubungan kedua ketentuan hukum internasional tersebut sangat erat sekali dan bersifat mutual comlimentary.

\section{B. Standarisasi Hukum Perlindungan Hak Ekonomi Dalam TRIPS Agreement Dan Ketentuan Hak Kekayaan Industri Di Indonesia}

Kendatipun TRIPS Agreement baru diberlakukan sejak 1 Januari 1995, TRIPS telah berhasil memberikan push dan coerce kepada negara-negara internasional untuk mematuhi perjanjian-perjanjian internasional berkaitan dengan hak kekayaan intelektual dan perdagangan global, termasuk dalam ruang lingkup ini adalah Paris Convention. Tindakan pemaksaan yang tidak mengenakkan banyak negara ini, terutama delevoping countries and least-developed countries, dimaksudkan untuk terciptanya keadilan (justice) dan pertumbuhan ekonomi global secara sehat dan competitive melalui karya intelektual manusia dan dalam rangka arus investasi (asing) dan transfer of technology and managements ${ }^{10}$. Hal ini dapat dibaca pada mukaddimah TRIPS yang antara lain menyebutkan "Recognizing also the special needs of the least-developed country Members in respect of maximum flexibility in the domestic implementation of laws and regulations in order to enable them to create a sound and viable technological base."

Beberapa standarisasi hukum perlindungan dalam bidang industrial property dalam ketentuan TRIPS dapat dijelaskan berikut ini.

\section{Ruang lingkup perlindungan}

Ruang lingkup perlindungan intellectual property rights yang diatur dalam TRIPS sama seperti yang diatur dalam Agreement on Establishing World Intellectual Property Organization (WIPO). Dalam Pasal 2 (viii) WIPO disebutkan bahwa ruang

10 Lihat WIPO, Guidelines For The Management And Exploitation of Patented And inventions of Research and Development Institutions in Developing Countries, Geneva, 1989, hlm. 10 dstnya. 
lingkup intellectual property rights meliputi : hak cipta, paten, merek, desain industri, rahasia dagang dan sirkuit terpadu.

Konsekuensi yuridis bagi negara-negara anggota (contracting parties) TRIPS Agreement bahwa negara-negara anggota harus memenuhi ketentuan TRIPS tersebut dengan membuat undang-undang yang memberikan perlindungan hukum terhadap semua bidang-bidang intellectual property rights tersebut. Dalam rangka memenuhi kewajiban untuk membuat undang-undang nasional bagi developing dan least-developed country TRIPS Agreement telah menetapkan aturan mainnya bagi kedua kelompok negara tersebut dalam Pasal 65 ayat (2) dan Pasal 66 ayat (1) TRIPS. Pasal 65 Ayat (2)

"Any developing country Member is entitled to delay for a further period of four years from the date of application, ...."

Pasal 66 Ayat (1)

"In view of the special needs and requirements of least-developed country Members, their economic, financial and administrative constraints, and their need for flexibility to create a viable technological base, such Members shall not be required to apply the provisions of this Agreement, other than Articles 3, 4 and 5, for a period of 10 years from the date of application as defined under paragraph 1 of Article 65. The Council for TRIPS shall, upon duly motivated request by a least-developed country Member, accord extensions of this period".

Dari kedua ketentuan diatas dapat dijelaskan, bahwa untuk negara berkembang kewajiban untuk memenuhi segala kewajiban yuridis berdasarkan TRIPS adalah 1 Januari 2000 yang merupakan penundaan selama 5 tahun dari sejak diberlakukannya TRIPS pada 1 Januari 1995. Sedangkan untuk negra-negara terkebelakang penundaan pemberlakuan TRIPS adalah sepuluh tahun dan akan jatuh tempo pada 1 Januari 2006. Kelihatannya pemberlakuan penuh ketentuan TRIPS untuk negara-negara terkebelakang sangat memungkinkan untuk ditunda lagi mengingat kemampuan dan kondisi ekonomi negara-negara tersebut ${ }^{11}$.

Sedangkan bagi negara-negara maju (developed country) kewajiban untuk memenuhi segala ketentuan TRIPS Agreement diberlakukan sejak mulai diberlakukannya TRIPS Agreement pada tanggal 1 Januari 1995.

Kelonggaran yang diberikan kepada negara-negara berkembang dan terkebelakang dimaksudkan untuk memberikan waktu yang relatif cukup untuk mempelajari dan mempersiapkan berbagai produk legislative dalam bentuk undang-undang dan peraturan pelaksana lainnya sebelum jatuh temponya pada tanggal 1 Januari 2000 bagi negara berkembang dan 1 Januari 2006 bagi negara terkebelakang ${ }^{12}$. Disamping itu, negara-negara itu juga harus membangun system

${ }^{11}$ Penundaan ini adalah sesuatu yang acceptable sepanjang negara terkebelakang tersebut mengajukan permohonan kepada Council For TRIPS dengan mengemukakan alasan-alasan ekonomi yang berdasarkan fakta.

12 J. Davis, Intellectual Property, 4 ${ }^{\text {th }}$ edition, Oxford University Press, 2012, Hlm. 10. 
penegakkan hukum (law enforcement) yang responsive dalam memerangi dan memberantas berbagai pelanggaran intellectual property rights di negaranegaranya. Pelanggaran-pelanggaran IPR pada hakekatnya tidak hanya menimbulkan kerugian (materil) bagi Negara-negara produser karya-karya intelektual semata, tetapi juga pelanggaran tersebut telah merusak system perekonomian suatu Negara dan mencirikan lemahnya law enforcement di Negara tersebut.

\section{Prinsip-prinsip hukum yang berlaku}

Beberapa prinsip hukum yang ditemukan dalam TRIPS Agreement dapat diuraikan berikut ini. Pertama, National Treatment Principle. Ketentuan Pasal 3 ayat (1) TRIPS menyebutkan"13: "Each Member shall accord to the nationals of other Members treatment no less than favourable than that it accords to its own nationals with regard to the protection of intellectual property ...."

Prinsip National Treatment ini dimaksudkan bahwa setiap negara anggota tidak dibenarkan untuk menerapkan perlakuan diskriminatif terhadap karya intelektual yang pencipta atau pemegang haknya bukan warga negaranya. Dengan demikian, perlindungan hukum yang diberikan tanpa memandang asal usul dari karya intelektual tersebut.

Kedua, Most-Favoured Nation Treatment Principle (MFN). Ketentuan mengenai prinsip atau azas hukum ini ${ }^{14}$ ditemukan pada Pasal 4 TRIPS yang berbunyi sebagai berikut:"With regard to the protection of intellectual property, any advantage, favour, privilege or immunity granted by a Member to nationals of any other country shall be accorded immediately and unconditionally to the nationals of all other Members. Exempted from this obligation are any advantage, privilege or immunity accorded by a Member :

a deriving from international agreements on judicial assistance and law enforcement of a general nature and not particularly confined to the protection of intellectual property.

b granted in accordance with the Rome Convention authorizing that the treatment accorded be a function not of national treatment but of the treatment accorded in another country .

$c$ in respect of the rights of performers, producers of phonograms and broadcasting organizations not provided under this Agreement.

d deriving from international agreements relates to the protection of intellectual property which entered into force prior to the entry into force of the Agreement Establishing the WTO, provided that such agreements are notified to the Council for Trade - Related Aspects of Intellectual Property Rights and do not constitute arbitrary or unjustifiable discrimination against nationals of other Members.

13 Ketentuan TRIPS ini berasal dari ketentuan Pasal 2 Paris Convention 1883.

14 Lihat juga WTO, Understanding the WTO, $3^{\text {rd }}$ edition, September 2003, hlm. 13 sebagaimana dikutip dalam www.wto. 
Prinsip MFN ini dimaksudkan sebagai pengecualian atas perlakuan dan tindakan diskriminatif oleh suatu negara kepada negara anggota lainnya atas alasan yang yang diperbolehkan oleh hukum. Jadi prinsip ini merupakan aturan hukum khusus terhadap prinsip non-diskriminasi, sepanjang pelaksanaannya tidak bertentangan dengan ketentuan Pasal 4 TRIPS tersebut.

\section{Jangka waktu perlindungan}

Mengenai jangka waktu perlindungan hak kekayaan industri TRIPS Agreement mengatur dengan jelas dan tegas, dan ketentuan ini harus dipatuhi atau harus dijadikan standar bagi Negara-negara anggota dalam merumuskan dan menetapkannya dalam ketentuan hukum nasional masing-masing Negara.

\section{a Merek}

Pasal 18 TRIPS $^{15}$ menyebutkan bahwa jangka waktu minimal untuk perlindungan merek adalah tujuh tahun dan sesudahnya dapat diperpanjang. Dapat dijelaskan disini, bahwa undang-undang nasional suatu Negara diperbolehkan untuk memberikan jangka waktu perlindungan lebih dari jangka waktu tujuh tahun tersebut. Seperti di Indonesia, UU No. 20 tahun 2016 Tentang Merek dan Indikasi Geografis memberikan jangka waktu perlindungan terhadap merek terdaftar selama 10 tahun dan dapat diperpanjang ${ }^{16}$.

\section{b Paten}

Jangka waktu perlindungan paten menurut Pasal 33 TRIPS Agreement ${ }^{17}$ minimal dua puluh (20) tahun sejak tanggal permohonan. Untuk jangka waktu perlindungan paten di Indonesia UU Paten Indonesia No. 13 Tahun 2016 telah sesuai dengan ketentuan TRIPS tersebut ${ }^{18}$. Sedangkan jangka waktu perlindungan untuk paten sederhana adalah 10 (sepuluh) tahun ${ }^{19}$.

\section{c Desain Industri}

Jangka waktu perlindungan desain industri tidak boleh kurang dari jangka waktu sepuluh (10) tahun. Hal ini dapat dilihat dari ketentuan Pasal 26 (3) TRIPS Agreement :"The duration of protection available shall amount to at least ten years". Ketentuan serupa juga ditemukan dalam Pasal 5 ayat (1) UU Deain Industri Indonesia No. 31 tahun 2001.

15 Article 18 TRIPS :'Initial registration, each renewal of registration, of a trademark shall be for a term of no less than seven years. The registration of a trademark shall be a renewable indefinitely.

16 Lihat Pasal 35 Ayat (1) UU No. 20 Tahun 2016 tentang Merek dan Indikasi Geografis; UU Merek dan IG ini mulai berlaku pada tanggal 25 November 2016; Lembaran Negara Tahun 2016 Nomor 252.

17 Article 33 TRIPS :"The term of protection available shall not end before the expiration of a period of twenty years counted from the filing date".

18 Demikian juga dengan Patentgezetz di Jerman juga memberikan jangka waktu perlindungan 20 tahun.

19 Lihat Pasal 22 UU No. 13 Tahun 2016 Tentang Paten memberikan perlindungan hukum 20 Tahun untuk Paten; sedangkan Pasal 23 UU No. 13 Tahun 2016 memberikan perlindungan hukum 10 Tahun untuk Paten Sederhana; TRIPS Agreement hanya mengatur mengenai jangka waktu perlindungan Paten. Undang-Undang Paten Singapore juga memberikan perlindungan paten selama 20 tahun, lihat N.W. Loon, op.cit., hlm 393. 


\section{d Sirkuit Terpadu}

Pasal 38 (1) TRIPS menetapkan bahwa jangka waktu perlindungan Sirkuit Terpadu ${ }^{20}$ minimal sepuluh (10) tahun. Pasal 4 Ayat 3 UU No. 32 Tahun 2001 memuat ketentuan yang sama dengan Article 38 (1) TRIPS Agreement tersebut.

\section{e Rahasia Dagang (Undisclosed Information)}

Untuk informasi rahasia atau rahasia dagang memang tidak ada jangka waktu perlindungannya. Selama informasi itu masih tersimpan kerahasiaannya, maka selama itu pula mendapat perlindungan hukum. Ketentuan TRIPS tersebut juga sudah sesuai dengan pengaturan dalam UU No. 30 tahun 2001 mengenai Rahasia Dagang di Indonesia.

Standarisasi hukum yang diberlakukan oleh masyarakat internasional dalam bidang perdagangan internasional dan hak kekayaan intelektual merupakan fenomena yang menciptakan globalisasi hukum dalam bidang perlindungan hak kekayaan industri. Pada kondisi yang demikian, hukum internasional memeliki hirarki yang lebih tinggi dari hukum nasional negranegara di dunia. Penyimpangan terhadap aturan ini oleh suatu negara akan mekekayaani konsekuensi yuridis, ekonomis dan politis dari masyarakat internasional, seperti sanksi ekonomi dari masyarakat internasional yang sudah barang tentu akan berdampak buruk terhadap ekonomi negara pelanggar ${ }^{21}$.

Globalisasi hukum di era globalisasi ini sangat wajar terjadi, karena globalisasi itu sendiri lahir karena tindak lanjut dari perkembangan hukum yang melewati lintas batas negara ${ }^{22}$. Undang-undang Paten telah pula mendorong lahirnya arus alih teknologi dari Negara-negara maju ke Negara-negara berkembang dan Negara terkebelakang dalam rangka pembangunan ekonomi nasional Negara tersebut ${ }^{23}$. Disamping itu globalisasi (hukum) juga sudah menjadi program masyarakat internasional terutama sekali dalam bidang hak asasi manusia, perdagangan internasional, ekonomi internasional dan hak kekayaan industri

\section{Kesimpulan}

Konvensi Paris 1883 dan TRIPS Agreement 1995 memiliki hubungan yang sangat erat. Konvensi Paris merupakan ketentuan internasional yang mengatur mengenai rejimrejim kekayaan intelektual dalam bidang industry, sedangkan TRIPS Agreement juga

${ }^{20}$ TRIPS menggunakan istilah "integrated circuit"; sedangkan UU No. 32 Tahun 2000 menggunakan istilah :Desain Tata Letak Sirkuit Terpadu".

21 Seperti misalnya Negara Indonesia harus sering kali melakukan perubahan terhadap undang-undang dalam bidang hak kekayaan intelektual dalam waktu yang relative singkat. Hal ini disebabkan belum singkronnya ketentuan nasional Indonesia tersebut dengan ketentuan TRIPS.

22 Munculnya berbagai kegiatan ekonomi transnasional seperti perusahaan Penanaman Modal Asing, masuknya berbagai produk asing ke dalam suatu Negara difasilitasi oleh aturan hukum seperti WTO Agreement, GATT, Licensing, Leasing, Franchise dan lain lain.

23 Lihat WIPO, op cit, hlm. 15. 
merupakan ketentuan internasional yang mengikat negara-negara yang lebih applicative dan menghubungkannya dengan tingkat ekonomi suatu negara. Dapat dikatakan bahwa Konvensi Paris merupakan the mother of law dalam bidang kekayaan intelektual, khususnya kekayaan industry.

Standarisasi hukum perlindungan hak kekayaan intelektual khususnya hak kekayaan industri (industrial property) bukanlah hal yang baru lahir, tetapi globalisasi hukum itu telah dicanangkan oleh masyarakat internasional jauh sebelum kehadiran organisasi dunia Liga Bangsa-Bangsa (League of Nations) ataupun Perserikatan Bangsa-Bangsa (United Nations) melalui penerimaan Paris Convention oleh sebagian besar Negara-negara Eropa pada tahun 1883.

Standarisasi hukum perlindungan hak kekayaan industri semakin gencar dikampanyekan oleh Negara-negara sebagai masyarakat internasional dengan kehadiran WTO dan TRIPS Agreement beserta ketentuan hukum internasional lainnya. Globalisasi hukum ini memang sesuatu yang tidak dapat dihindari oleh banyak Negara, terutama oleh Negara-negara berkembang dan Negara terkebelakang, karena pada kenyatannya Negara-negara tersebut sangat memerlukan banyak hal dari Negara-negara maju untuk memperbaiki dan memajukan perekonomian nasional Negara tersebut. Standarisasi hukum perlindungan hak kekayaan industri ini pada kenyataannya juga akan mampu menumbuhkan kepercayaan asing terhadap system hukum Negara tersebut asalkan law enforcement juga mampu memberikan kepastian hukum (legal certainty) dan keadilan (justice). Peraturan perundang-undangan di Indonesia sejauh ini sudah sejalan dengan ketentuan internasional Konvensi Paris 1883 dan TRIPS Agreement 1995. 
UIRLawReview. 5(1): 19-29

\section{Daftar Pustaka}

Davis, Jennifer, Intellectual Property Law, $4^{\text {th }}$ Edition, Oxford, London, 2012.

European Commission, Strategic Dimensions of Intellectual Property Rights in the Context of S\&T Policy, Belgium, June 1999.

Galvez-Behar, Gabriel, The 1883 Paris Convention and the Impossible Unification of Industrial Property, in : Graeme Gooday and Wilf Steven, Patent Cultures, Cambridge University Press, 2020.

Gooday, Graeme And Steven, Wilf, Patent Cultures, Cambridge University Press, 2020.

Loon, Ng-Loy Wee, Law of Intellectual Property of Singapore, Thomson Sweet \& Maxwell Asia, Singapore, 2008.

Syafrinaldi, Hukum Tentang Perlindungan Hak Kekayaan Intelektual Dalam Menghadapi Era Globalisasi, UIR Press, Pekanbaru, 2010.

---------, Menuju Era Hak Kekayaan Intelektual (Paper yang disampaikan pada kuliah umum mahasiswa baru UIR Tahun Akademik 2000/2001 pada tanggal 28 Agustus 2000)

----------, Peranan Hukum Dalam Pengembangan Ekonomi (Paper disampaikan pada Diskusi Panel di Komisi Hukum Nasional Jakarta pada tanggal 7 September 2000 di Hotel Indonesia Jakarta)

---------, Hukum, Hak Kekayaan Intelektual Dan Pembangunan, UIR Press, Pekanbaru, 2002.

WIPO, Guidelines For The Management And Exploitation of Patented And inventions of Research and Development Institutions in Developing Countries, Geneva, 1989, hlm. 10 dstnya.

WTO, WTO, Understanding the WTO, $3^{\text {rd }}$ edition, September 2003, hlm. 13 sebagaimana dikutip dalam www.wto 